\title{
Microstructure evolution of Al-Si hypoeutectic alloys prepared by controlled diffusion solidification
}

Abbas Khalaf ( $\sim$ abbasklf6@yahoo.com )

McMaster University https://orcid.org/0000-0002-0157-8491

\section{Research Article}

Keywords: Controlled diffusion solidification, Al-Si alloys, microstructure, optical metallography

Posted Date: January 17th, 2022

DOI: https://doi.org/10.21203/rs.3.rs-1255243/v1

License: (c) (i) This work is licensed under a Creative Commons Attribution 4.0 International License. Read Full License 


\section{Abstract}

The possibility of changing the dendritic microstructure associated with the conventional casting processes of hypoeutectic Al-Si alloys to non-dendritic microstructure by using the controlled diffusion solidification process (CDS) has been investigated. The successful CDS process depends on mixing two precursor alloys heated at a superheat condition near their respective liquidus temperature. Experimental work and simulation work using Ansys software was carried out in the present study by employing Al-Si and Al-Cu systems. This study investigates the effect of the content of the two precursor alloys, the mass ratio changing from 2.6 to 8.3 , and the superheat of the first precursor alloy on changing the microstructure. The experimental results show that the pure aluminum used as the first precursor alloy needs more undercooling and agitation during the mixing to form the non-dendritic microstructure compared with hypoeutectic Al-Si alloys. Further, mixing pure aluminum with hypereutectic alloy can change the microstructure of hypoeutectic alloys leading to extending the possibility to choose the second precursor alloy. The results also show that a higher mass ratio is preferred when mixing pure aluminum with hypoeutectic alloy. Furthermore, the microstructure of the alloy $\mathrm{Al}-6.45 \mathrm{Si}-4 \mathrm{Cu}-0.5 \mathrm{Mg}$ $0.66 \mathrm{Fe}-0.66$ wt $\% \mathrm{Zn}$ was successfully changed via the CDS process by mixing Al- $7.75 \mathrm{Si}-0.79 \mathrm{Fe}-0.78 \mathrm{Zn}-$ $0.6 \mathrm{wt} \% \mathrm{Mg}$ at $2^{\circ} \mathrm{C}$ superheat into $\mathrm{Al}-24 \mathrm{wt} \% \mathrm{Cu}$ at around $5^{\circ} \mathrm{C}$ superheat. The simulation results show that lower air bubbles and better distribution of the two precursor alloys happen during the mixing step when using the Al-Cu system.

\section{Introduction}

The hypoeutectic aluminum-silicon alloys are abundant among the other alloys used in the casting process. The Al-Si alloys have wide application in domestic, automotive, and aerospace applications due to their low cost, good castability, favorable mechanical properties, and high strength to weight ratio [14].

The controlled diffusion solidification (CDS) process depends on mixing two precursor alloys in a liquid state innovated to enable casting of aluminum wrought alloys to near-net-shape resulting to form a nondendritic microstructure similar to that forming in the semi-solid processes [5-10]. Khalaf [11] mixed pure aluminum into Al-Si eutectic alloy to make Al-1.8 wt\%Si as a resultant alloy. The results show that the non-dendritic morphologies form the microstructure of the final solidified alloy. Khalaf et al. [6, 1016] used the CDS process to mix pure aluminum with Al-Cu binary alloys that have different solute contents, the results show that the microstructure forms from globular morphologies, globular mixed with rosette morphologies, and rosette mixed with dendritic morphologies, where the change in the microstructure strongly depends on the mass ratio and the undercooling of the first precursor alloy. The undercooling strongly depends on the difference between the initial temperatures of the two precursor alloys prior to the mixing step $[12,17]$.

Ghiaasiaan et al $[9,18-21]$ worked on the heat treatment of 7xxx (Al-Zn-Mg-Cu) wrought alloys that were made via the CDS process. Ghiaasiaan mixed two alloys instead of mixing pure aluminum into alloy 
using tilt pour gravity casting equipment that has a permanent steel mold heated to $375^{\circ} \mathrm{C}$ [22]. The results show that the non-dendritic morphologies form the microstructure of the resultant alloy. Yang et al.[23] used the CDS process to make 7050 alloy by mixing pure aluminum into Al-Zn11.2-Mg5- Cu3 (wt\%) alloy, the non-dendritic microstructure forms the resultant alloy. Khalaf [17] used Al-Zn binary alloys to study the microstructure of the CDS process, where pure aluminum was mixed into Al-Zn binary alloys at different mass ratios to make Al-4.5 wt\% $\mathrm{Zn}$ as a resultant alloy. The final results were compared with Al-Cu alloys. Khalaf found that the non-dendritic microstructure has globular, rosettes, and dendritic morphologies coexisting in the entire samples of different experiments, where the ratio between the morphologies depends on the mass ratio, crucible temperature, and the difference between the initial temperatures of the mixed precursor alloys.

There are few studies published regarding changing the microstructure of the hypoeutectic Al-Si alloys by using the CDS process. This work was dedicated to changing the microstructure of the hypereutectic Al-Si alloys formed via the CDS process. Experimental and simulation evidence coupled with optical microstructure images support the discussion in this study.

\section{Experiments}

Table 1 presents the list of the experiments carried out along with the independent parameters and constants. The experimental procedure, the crucible and funnel dimensions, and the schematic diagram of the setting up of the funnel and the crucible for the CDS process have been discussed in detail previously[11, 16, 17]. Fig. 1(a) shows the Alloy 1 and Alloy2 with their temperatures and concentrations placed on the Al-Si phase diagram, where Alloy 1 is pure aluminum with $T_{1}$ fixed at $665^{\circ} \mathrm{C}$ for the CDS experiments named Ex1 to Ex7 involved in Table 1. Fig. 1(b) shows the cooling curve and the first derivative curve (dT/dt) for the pure aluminum that was used in the experiments. In Fig. 1(b), the intercept point is $660.2^{\circ} \mathrm{C}$ representing the melting point of the used pure aluminum.

The CDS experiments named Ex1and Ex2 were carried out by mixing Alloy 1 into Alloy2 through a 9-mm diameter funnel to make the resultant alloy (Alloy3). Ex 1 was carried out by mixing Alloy 1 into Alloy2 (Al$12.6 \mathrm{wt} \% \mathrm{Si}$ ) with $\mathrm{mr} 6$ to make $1.8 \mathrm{wt} \% \mathrm{Si}$ as a resultant alloy. Fig. 1(c) shows the cooling curve and the first derivative curve (dT/dt) for the Al-12.6 wt\%Si eutectic alloy that was used in the experiments. In Fig. 1 (c), the intercept point is $573^{\circ} \mathrm{C}$ representing the liquidus temperature of the used eutectic alloy. Ex 2 was carried out by mixing Alloy 1 into Alloy 2 (Al-33 wt\%Cu) with $m r 6$ to make $4.6 \mathrm{wt} \% \mathrm{Cu}$ as a resultant alloy. The temperature of the mixture of Ex1 and Ex2 was collected by two thermocouples named lower thermocouple and upper thermocouple inserted prior to the mixing step in the bottom and the middle of the crucible, respectively. Elaboratory discussion about mixing through a funnel was already reported [13].

The CDS experiments named Ex3, Ex5, and Ex7 were carried out by direct mixing of Alloy 1 into Alloy 2 to make the resultant alloy (Alloy3). Ex3 was carried out by mixing Alloy 1 into Alloy2 (Al-12.6 wt\%Si) with $\mathrm{mr}$ 8.3 to make $1.4 \mathrm{wt} \% \mathrm{Si}$ as a resultant alloy. After the mixing step, the mixture was directly poured into an empty-backed clay crucible heated at $570^{\circ} \mathrm{C}$. Ex 4 was carried out by re-melting a part of the solidified 
sample of Ex3 and directly pouring the melt into an empty-backed clay crucible that was heated at $570^{\circ} \mathrm{C}$. Ex4 represents a conventional solidification. Ex5 was carried out by mixing Alloy 1 into Alloy2 (Al-12.6 wt\%Si) with $m r 3$ to make $3.1 \mathrm{wt} \% \mathrm{Si}$ as a resultant alloy. After the mixing step, the mixture was directly poured into an empty steel crucible heated at $580^{\circ} \mathrm{C}$. Ex6 was carried out by re-melting a part of the solidified sample of Ex5 and directly pouring the melt into an empty steel crucible that was heated at $580^{\circ} \mathrm{C}$. Ex6 represents a conventional solidification. Ex7 was carried out by mixing Alloy 1 into a hypereutectic alloy (Alloy2 (Al-15 wt\%Si)) with $\mathrm{mr} 2.6$ to make $4.5 \mathrm{wt} \% \mathrm{Si}$ as a resultant alloy. Fig. 1 (d) shows the cooling curve and the first derivative curve (dT/dt) for the Al-15 wt\%Si hypereutectic alloy that was used to make $E x 7$. In Fig. 1 (d), the intercept point is $609^{\circ} \mathrm{C}$ representing the liquidus temperature of the Al-15wt\%Si alloy used in the study.

Table 1

Experimental designations with independent parameters and constants for the laboratory experiments.

\begin{tabular}{|c|c|c|c|c|c|c|c|c|c|c|}
\hline \multirow[t]{2}{*}{ Designation } & \multicolumn{4}{|c|}{ Alloy 1} & \multicolumn{4}{|c|}{ Alloy 2} & \multirow[t]{2}{*}{$m r$} & \multirow{2}{*}{$\begin{array}{l}\text { Alloy3 } \\
\text { Co } \\
\text { (wt\%) }\end{array}$} \\
\hline & $\begin{array}{l}\mathrm{m} 1 \\
(\mathrm{~g})\end{array}$ & \multicolumn{2}{|c|}{$\begin{array}{l}\mathrm{T}_{1} \mathrm{C}_{1} \\
\left({ }^{\circ} \mathrm{C}\right)(\mathrm{wt} \%)\end{array}$} & $\begin{array}{l}\mathrm{T}_{\mathrm{L} 1} \\
\left({ }^{\circ} \mathrm{C}\right)\end{array}$ & $\begin{array}{l}\mathrm{m} 2 \\
(\mathrm{~g})\end{array}$ & \multicolumn{2}{|c|}{$\begin{array}{l}\mathrm{T}_{2} \mathrm{C}_{2} \\
\left({ }^{\circ} \mathrm{C}\right)(\mathrm{wt} \%)\end{array}$} & $\begin{array}{l}\mathrm{T}_{\mathrm{L} 2} \\
\left.{ }^{\circ} \mathrm{C}\right)\end{array}$ & & \\
\hline \multirow[t]{2}{*}{ Ex1 } & 284 & 665 & 0 & 660 & 47 & 582 & 12.6 & 573 & 6 & 1.8 \\
\hline & & & & & & & \multicolumn{4}{|l|}{ Si } \\
\hline \multirow[t]{2}{*}{ Ex2 } & 290 & 664 & 0 & 660 & 48 & 552 & 33 & 549 & 6 & 4.6 \\
\hline & & & & & & & \multicolumn{4}{|l|}{$\mathrm{Cu}$} \\
\hline \multirow[t]{2}{*}{ Ex3 } & 290 & 665 & 0 & 660 & 35 & 580 & 12.6 & 573 & 8.3 & 1.4 \\
\hline & & & & & & & \multicolumn{4}{|l|}{ Si } \\
\hline Ex4 & \multicolumn{10}{|c|}{ Part of Ex3 sample re-melted at $665^{\circ} \mathrm{C}$ and poured directly into hot crucible at $570 \mathrm{C}$} \\
\hline \multirow[t]{2}{*}{ Ex5 } & 252 & 665 & 0 & 660 & 78 & 580 & 12.6 & 573 & 3 & 3.1 \\
\hline & & & & & & & \multicolumn{4}{|l|}{ Si } \\
\hline Ex6 & \multicolumn{10}{|c|}{$\begin{array}{l}\text { Part of Ex5 sample remelted at } 665^{\circ} \mathrm{C} \text { and poured into a hot steel crucible heated at } \\
580^{\circ} \mathrm{C}\end{array}$} \\
\hline \multirow[t]{2}{*}{$E \times 7$} & 298 & 665 & 0 & 660 & 116 & 613 & 15 & 609 & 2.6 & 4.5 \\
\hline & & & & & & & \multicolumn{4}{|l|}{$\mathrm{Si}$} \\
\hline
\end{tabular}

Ex8 and Ex9 were carried out by mixing alloy with alloy, where Alloy 1 was directly mixed into Alloy2 to make Alloy3. Table 2 presents the independent parameters and constants for the experiments. Fig. 1(e) shows the cooling curve and the first derivative curve (dT/dt) for the Alloy 1 that was used to make Ex9 taken as an example. In Fig. $1(\mathrm{e})$, the intercept point is $602^{\circ} \mathrm{C}$ representing the liquidus temperature of the Alloy1. Fig. 1(f) shows half of the sample produced by the CDS process. Specimens pointed by a circle 
(A) and (B) represent the middle and the edge of the sample, respectively. The specimens were prepared for optical microscope images.

Table 2

Experimental designations with independent parameters and constants for the laboratory experiment named Ex8 and Ex9.

\begin{tabular}{|c|c|c|c|c|c|c|c|c|}
\hline & Alloy1 & $\begin{array}{l}T_{L 1} \\
\left({ }^{\circ} \mathrm{C}\right)\end{array}$ & $\begin{array}{l}T_{1} \\
\left({ }^{\circ} \mathrm{C}\right)\end{array}$ & Alloy2 & $\begin{array}{l}T_{L 2} \\
\left({ }^{\circ} \mathrm{C}\right)\end{array}$ & $\begin{array}{l}T_{2} \\
\left({ }^{\circ} \mathrm{C}\right)\end{array}$ & $m r$ & Alloy3 \\
\hline \multirow[t]{2}{*}{ Ex8 } & \multirow{2}{*}{$\begin{array}{l}\text { Al-5.36Cu-0.88Fe- } \\
0.67 \mathrm{Mg}-3.9 \mathrm{Si}-0.88 \mathrm{Zn}\end{array}$} & \multirow[t]{2}{*}{618} & \multirow[t]{2}{*}{630} & Al- & \multirow[t]{2}{*}{585} & \multirow[t]{2}{*}{600} & \multirow[t]{2}{*}{3} & Al- \\
\hline & & & & $13.5 w t \% S i$ & & & & 6.45Si-4Cu- \\
\hline \multirow[t]{2}{*}{ Ex9 } & Al- & \multirow[t]{2}{*}{602} & \multirow[t]{2}{*}{604} & Al- & \multirow[t]{2}{*}{590} & \multirow[t]{2}{*}{593} & \multirow[t]{2}{*}{4.5} & $0.66 \mathrm{Zn}$ \\
\hline & $\begin{array}{l}\text { 7.75Si-0.79Fe-0.78Zn- } \\
0.6 \mathrm{Mg}\end{array}$ & & & $24 w t \% C u$ & & & & \\
\hline
\end{tabular}

\section{Phase Diagram Consideration}

Figure 2 (a) shows a comparison between the phase diagram of the hypoeutectic alloys for Al-Si and AlCu alloys. In Figure 2 (a), $T_{L}$ and $T_{S}$ were the liquidus and the solidus temperature lines, respectively. The $\mathrm{Al}-\mathrm{Cu}$ system was chosen to compare with the Al-Si system because the microstructure of the Al-Cu alloys easily and successfully changes to non-dendritic by using the CDS process $[6,7,24-27,10-17]$. Figure 2 (a) can be employed to make two resultant alloys that have the same content of $4.5 \mathrm{wt} \%$ taken as an example. Where points $(\mathrm{C})$ and $(\mathrm{E})$ represent the resultant alloys that have content of $\mathrm{Al}-4.5 \mathrm{wt} \% \mathrm{Cu}$ and $\mathrm{Al}-$ $4.5 \mathrm{wt} \% \mathrm{Si}$, respectively. Unlimited contents of Alloy 1 and Alloy 2 can be chosen to make the two alloys that could be mixed to make the resultant alloy by the CDS process. Pure aluminum with $5^{\circ} \mathrm{C}$ superheat represented at point (A) can be mixed with eutectic alloys that have $5^{\circ} \mathrm{C}$ superheat represented by points (B) and (C) for Al-Cu and Al-Si systems to make the resultant alloys, respectively. According to the phase diagram, the maximum difference in the initial temperature between the pure aluminum and the eutectic alloys was 110 and $83^{\circ} \mathrm{C}$ employed by Al-Cu and Al-Si systems, respectively. Where, a higher difference between the temperatures of the two precursor alloys that are mixed at a temperature near to their respective liquidus temperature leads to a higher undercooling of the first precursor alloy happening during the mixing step resulting in a drastic increase in the nucleation rate [16, 17]. In addition, according to the level rule, the mass ratios $(m r=m 1 / m 2)$ required to make the resultant alloys are 6.3 and 1.82 for Al$\mathrm{Cu}$ and $\mathrm{Al}-\mathrm{Si}$, respectively. One can suggest that the lower difference in the initial temperature for the Al-Si system decreases the undercooling of Alloy1during the mixing step, this leads to a decrease in the nucleation rate. In addition, the lower mass ratio increases the amount of the dendritic morphologies forming among the globular and rosette morphologies creating in the microstructure of the hypoeutectic alloys formed by the CDS process [12,15-17]. According to that, the microstructure of the Al-Si hypoeutectic alloys is expected to have more dendritic morphologies forming in the entire product made by the CDS process especially for the alloys that have a silicon content of more than $4.5 \mathrm{wt} \% \mathrm{Si}$ when mixing pure aluminum into a hypoeutectic alloy. 


\section{Simulation Consideration}

Ansys fluent software was used to simulate the mixing of Alloy 1 into Alloy 2 for the experiments Ex 1 and Ex2 illustrated in Table 1. The 2D axisymmetric model was employed to simulate the mixing step using heat transfer, $\mathrm{k}-\varepsilon$ turbulence model, and the volume of fluid (VOF) with three phases model. Where dry air, pure aluminum (Alloy1), and Alloy2 (Al-12.6 wt\%Si for Ex1 and Al-33 wt\%Cu for Ex2) were the three phases coexisting in the simulation. Eqs. (1) to (3) represent the Navier stocks equation, continuity equation, and heat equation numerically solved in the simulation. Fig. 2 (b) shows the initial condition of the density distribution and the locations of the Alloy1, Alloy2, and the Air in the funnel and the crucible.

$$
\frac{\partial \mathrm{u}}{\partial \mathrm{t}}+\rho \mathrm{u} \cdot \nabla \mathrm{u}=\nabla \cdot[-\mathrm{p}+\mu(\nabla \mathrm{u})]
$$

1

$$
\rho \frac{\partial \rho}{\partial t}+\rho \nabla \cdot \mathrm{u}=0
$$

$$
\rho \mathrm{C}_{\mathrm{p}} \frac{\partial \mathrm{T}}{\partial \mathrm{t}}+\rho \mathrm{C}_{\mathrm{p}} \mathrm{u} . \nabla \mathrm{T}=\nabla \cdot(\mathrm{K} \nabla \mathrm{T})
$$

3

The parameters used in Eqs. (1) to (3) were $\rho=2375\left(\mathrm{~kg} / \mathrm{m}^{3}\right)[13,15]$ is the density of the pure aluminum (Alloy1) at liquidus temperature, Eq. (4) represents the density of the liquid phase for hypoeutectic Al-Si alloys extrapolated from Thermo-Calc data as a function of the temperature and silicon content (wt\%). In Eq. (4), $A_{L}=2528+3.374 C_{S}, B_{L}=0.23234+(4 E-5) C_{S i}$. Eq. (5) [15] represents the density of the Al-Cu hypoeutectic alloys extrapolated from data obtained from Factsage software to cover a range of copper concentrations and temperatures from (0 to 33$) \mathrm{wt} \% \mathrm{Cu}$ and $(549.8 \text { to } 700)^{\circ} \mathrm{C}$, respectively. In Eq. (5), $\beta_{T}=-4.032+(1.654 E-2) T-(2.53 E-5) T^{2}+(1.23 E-8) T^{3}$ and

$\beta_{C}=22.19678+(0.1629) C_{C u}+(9.0973 E-4) C_{C u}^{2}+(2.004 E-5) C_{C u}^{3}$ are variables that depend on the temperature and copper concentration, respectively. Fig. 2 (c) shows a comparison between the density of the $\mathrm{Al}-12.6 \mathrm{wt} \% \mathrm{Si}$ and $\mathrm{Al}-33 \mathrm{wt} \% \mathrm{Cu}$, showing that the density of Al-Cu eutectic alloy is significantly bigger than that of Al-Si eutectic alloy. Further in Eqs. (1) to (4), $C_{P}$ is the specific heat, where $C_{P-A l}=1179$ [28], $C_{P-A l-33 C u}=953.9 \mathrm{~J} \mathrm{~kg}^{-1} \mathrm{~K}^{-1}[12], C_{P-A l-12.6 S i}=1106 \mathrm{~J} \mathrm{~kg}^{-1} \mathrm{~K}^{-1}$ was extrapolated in the same way for Al-Cu system [12]. $K_{L}=70$ [29] and $K_{L}=95 \mathrm{~W} \mathrm{~m}^{-1} \mathrm{~K}^{-1}$ [30] for Al-Si and Al-Cu system respectively. $\mu=1.3 \mathrm{mPa}[28]$ is the viscosity of pure aluminum at the melting temperature $\left(T_{m}\right)$, and Eq. (6) [31] evaluates the viscosity ( $\eta_{\text {Alloy }}$ ) of a multi-component alloy that has $(N)$ species. In Eq. (6), $\mathrm{x}_{\mathrm{i}}, \eta_{i}^{O}$ and $\mathrm{E}_{\mathrm{i}}$ were alloy content in mole fraction, pre-exponential parameter, and the activation energy for pure melts, where $\eta_{A l}^{o}=0.163 \mathrm{mPa} . s, \eta_{S i}^{o}=0.107 \mathrm{mPa} . s, \eta_{C u}^{o}=0.398 \mathrm{mPa} . s_{,} \mathrm{E}_{\mathrm{Al}}=16114$ 
J.mole ${ }^{-1}, \mathrm{E}_{\mathrm{Si}}=23488 \mathrm{~J} \mathrm{~mole}^{-1}$, and $\mathrm{E}_{\mathrm{Cu}}=25996 \mathrm{~J} \cdot \mathrm{mole}^{-1}$ [32]. Further in $\mathrm{Eq}(6), \Delta \mathrm{H}_{\text {sol }}$ is the heat of solution evaluated in Eq. (7). Where the solute content was in the mole fraction, $\Omega$ is the regular solution parameter evaluated in Eq. (8) [33]. In Eq. (8) $\mathrm{L}^{0}{ }_{\mathrm{Al}-\mathrm{Si}}=-11340-1.234 \mathrm{~T}, \mathrm{~L}^{1}{ }_{\mathrm{Al}-\mathrm{Si}}=-3531+1.36 \mathrm{~T}$ and $\mathrm{L}^{2}{ }_{\mathrm{Al}-\mathrm{Si}}=2265$ are the parameters of silicon in aluminum alloy[34], and $\mathrm{L}^{0}{ }_{\mathrm{Al}-\mathrm{Cu}}=-66622+8.1 \mathrm{~T}, \mathrm{~L}^{1} \mathrm{Al}-\mathrm{Cu}=64800-90.8 \mathrm{~T}+10 \mathrm{~T}(\mathrm{Ln}(\mathrm{T}))$ and $\mathrm{L}^{2} \mathrm{Al}-\mathrm{Cu}=-2812$ are the parameters of copper in aluminum alloy [35]. According to the calculation from Eqs. (6) to (8), $\mu=1.4$ and $5.6 \mathrm{mPa}$ are the viscosity of $\mathrm{Al}-12.6 \mathrm{wt} \% \mathrm{Si}$ and $\mathrm{Al}-33 \mathrm{wt} \% \mathrm{Cu}$ at their respective liquidus temperature. The other parameters were obtained from the default of the ANSYS software.

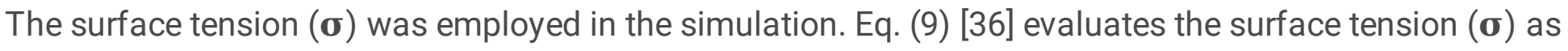
a function of temperature that starts from the liquidus temperature. In Eq. (9), $\boldsymbol{\sigma}=0.868 \mathrm{Nm}^{-1}$ for pure aluminum at melting temperature [26], $\boldsymbol{\sigma}_{\mathrm{L}}=0.824 \mathrm{Nm}^{-1}$ and $(\mathrm{d} \boldsymbol{\sigma} / \mathrm{dT})=\left(-3.1 \times 10^{-4}\right) \mathrm{Nm}^{-1} \mathrm{~K}^{-1}$ for Al-12 wt\%Si [37], $\boldsymbol{\sigma}_{\mathrm{L}}=0.951 \mathrm{Nm}^{-1}$ and $(\mathrm{d} \boldsymbol{\sigma} / \mathrm{dT})=\left(-0.92 \times 10^{-4}\right) \mathrm{Nm}^{-1} \mathrm{~K}^{-1}$ for Al-30 wt\%Cu [36]. Fig. 2 (d) shows the comparison between the surface tension of Al-30 wt\%Cu hypoeutectic alloy and $\mathrm{Al}-12 \mathrm{wt} \% \mathrm{Si}$ hypoeutectic alloy, where both alloys lay near the eutectic alloy for Al-Cu and Al-Si systems.

$$
\rho\left(\mathrm{T}, C_{S i}\right)=A_{L}-B_{L} \mathrm{~T}
$$

4

$$
\rho\left(T, C_{C u}\right)=3150+\beta_{T}(T-549.8)+\beta_{C}\left(C_{C u}-33\right)
$$

$$
\operatorname{Ln}\left(\eta_{\text {Alloy }}\right)=\sum_{i=1}^{N} x_{i} \ln \left(x_{i} \eta_{i}^{o}\right)+\left(\left\{\sum_{i=1}^{N} x_{i} E_{i}+\Delta H_{\text {sol }}\right\} \mid R_{o} T\right)
$$

6

$$
\Delta H_{\text {sol }}=\Omega C_{\text {Solute }} C_{A l}
$$

7

$$
\Omega=\sum_{i=0}^{j} L^{i}\left(C_{A l}-C_{\text {Solute }}\right)^{i}
$$

8

$$
\sigma(T)=\sigma_{L}+(d \sigma \mid d T)\left(T-T_{L}\right)
$$




\section{Results And Discussion}

The experiments Ex 1 and Ex2 involved in Table 1 were carried out by mixing Alloy 1 (pure aluminum) with Alloy2 (eutectic alloy). The Alloy1 and Alloy2 were the precursor alloys placed in the phase diagram at points (A), (B), and (D) shown in Fig. 2 (a). The conditions of Ex2 is almost similar to that of Ex1 for Alloy $1, m_{1}, m_{2}, T_{1}$, and $m$ r. Fig. 3 (a) to (d) show a comparison between the microstructure of the experiments Ex1 and Ex2. Fig. 3 (a) and (b) show optical microstructure images of the CDS sample for the experiment denoted as Ex1. Fig. 3 (a) shows an optical microstructure image for the specimen located in the middle of the sample. The specimen is pointed by (A) in Fig. 1(f). In Fig. 3 (a) globular mixed with rosette morphologies would form the non-dendritic microstructure. Fig. 3 (b) shows an optical microstructure image for the specimen located at the edge of the sample. The specimen is pointed by (B) in Fig. 1(f). In Fig. 3 (b) dendritic morphologies mixed with rosette morphologies form the microstructure, where the dendrites dominate the microstructure. Fig. 3 (c) and (d) show optical microstructure images of the specimens located in the middle and the edge of the sample for the CDS experiment denoted as Ex2, respectively. In Fig. 3 (c) and (d), globular mixed with few rosette morphologies would form the nondendritic microstructure. The microstructure results indicated in Fig. 3 (a) to (d) show that the undercooling employed from Alloy2 for the Al-Cu system shown in Fig. 2 (a) strongly affects the nondendritic microstructure leading to the creation of the globular morphologies that dominate the entire microstructure of the sample compared with that for the Al-Si system.

Figure 3 (e) shows the thermal curves of the experiments $E x 1$ and $E x 2$ drawn for the data collected by the lower thermocouple inserted in the crucible of Alloy 2 prior to the mixing step. In Figure 3 (e), the temperature data was superimposed to start at the same time to ease the comparison between the thermal curves, further, points $(A)$ and $(C)$ represent the starting of mixing of Alloy 1 into Alloy 2 and points (B) and (D) represent the maximum temperature of the mixture at the end of the mixing step for Ex 1 and Ex2, respectively. Figure 3 (e) also shows that thermal recalescence, some of them pointed by arrows, appear as an oscillation in the temperature happening between the starting and the end of mixing in the thermal curves for the experiments $E x 1$ and $E x 2$, where this kind of thermal recalescence indicates that the nucleation events occur during the mixing step of the CDS process [12]. In addition, the difference between the starting of mixing temperatures (points $(A)$ and $(C)$ ) was around $582-552=30^{\circ} \mathrm{C}$, and the difference between the maximum temperatures (points (B) and (D)) was around $657-650=7^{\circ} \mathrm{C}$. According to that, the nucleation can occur in both the Al-Si and Al-Cu systems, and the heat issued from the nucleation events during the mixing of pure aluminum into $\mathrm{Al}-33 \mathrm{wt} \% \mathrm{Cu}$ is significantly bigger than that when mixing pure aluminum into $\mathrm{Al}-12.6 \mathrm{wt} \% \mathrm{Si}$ although the conditions of Ex2 is almost similar to that of Ex 1 for Alloy $1, m_{1}, m_{2}, T_{1}$, and $m r$.

Figure 4 (a) to (d) show the simulation results of density distribution at $0.4 \mathrm{~s}$ for $E x 1$ and $E x 2$ experiments illustrated in Table 1. Figure 4 (a) to (c) show the simulation results of the density distribution for the Ex1 experiment. Figure 4 (b) shows a magnified area at the funnel region shown in Figure 4 (a), showing that the liquid surface that was pointed by arrows forms as a curved shape happening because of the effect of the surface tension employed in the calculation. This appears in all liquid surfaces for Al-Si and Al-Cu 
systems at all times in the present study when employing the surface tension in the simulation. Figure 4 (c) and (d) show magnified areas of the mixture in the crucible region for $E x 1$ and $E x 2$ respectively. The crucible region is pointed by the square in Figure 4 (a) taken as an example. In Figure 4 (c) and (d), the density distribution for $E X 2$ is significantly different compared with $E x 1$, wherein better distribution of Alloy 2 in the mixture for the Al-Cu system. Further, air bubbles that were pointed by arrows appear in both experiments forming at the contact area located between the stream of Alloy 1 and Alloy2. The simulation results show that the air bubbles forming in the Al-Cu system are significantly less than that for the Al-Si system shown in Figure 4 (d). One can suggest that the air bubbles forming during the mixing step strongly depend on the difference between the densities and the viscosities of the mixed alloys.

Figure 5 (a) to (f) show the simulation results of density distribution for the mixture in the crucible taken during the mixing step at $0.8 \mathrm{~s}, 1.2 \mathrm{~s}$, and at the end of the mixing step for the experiments named Ex 1 and Ex2 illustrated in Table 1. Where Figure 5 (a) and (b) show the density distribution after 0.8 s, Figure 5 (c) and (d) show the density distribution after 1.2s, and Figure $5(\mathrm{e})$ and (f) show the density distribution at the end of mixing for Ex1 and Ex2, respectively. In Figure 5 (a) to (f), the eutectic alloy for the Al-Cu system has a better probability to break into small masses, this leads to making better distribution of Alloy2 in the entire mixture. One can suggest that the better distribution of the two precursor alloys during the mixing step could affect forming a non-dendritic microstructure in the CDS process. Further, the simulation results show that the air bubbles distribute in the entire mixture by the agitation happening during the mixing, where some of them escape to the environment and the other exists in the mixture till the end of the mixing step.

Figure 6 (a) and (b) show typical microstructure images of the specimens located in the middle and the edge of the CDS sample for the experiment denoted as Ex3 in Table 1, respectively. Figure 6 (a) shows an optical microstructure image for the specimen located in the middle of the sample, showing that the nondendritic microstructure forms the middle of the CDS process sample. In Figure 6 (a) globular mixed with rosettes and a few dendritic morphologies would form the non-dendritic microstructure. Figure 6 (b) shows an optical microstructure image for the specimen located at the edge of the sample. In Figure 6 (b) the non-dendritic microstructure also has globular mixed with rosette and dendritic morphologies form in the edge of the sample. The microstructure of the experiment Ex3 differs from that forming in Ex 1 especially at the edge of the sample. One can suggest that the experiment Ex3 was carried out by increasing the mass of Alloy 1 (pure aluminum) and decreasing the mass of Alloy2 (eutectic alloy), the nucleation starts from Alloy 1 (pure aluminum with $665^{\circ} \mathrm{C}$ ) that is undercooled during the mixing because the mixing happens into the crucible of $A$ lloy2 that has a lower temperature $\left(580^{\circ} \mathrm{C}\right)[16,17]$. Additionally, The decrease of Alloy 2 results in decreasing in the dendritic morphologies forming in the microstructure because the Alloy 2 is prone to make the dendritic microstructure, especially when choosing pure aluminum as Alloy 1 in the CDS process [17]. Further, the mixture was poured directly after mixing step into an empty crucible heated at $555^{\circ} \mathrm{C}$. This leads to an increase in the nucleation rate in Alloy 1 and makes an agitation applying to the mixture leading to a re-distribution of the morphologies forming in the mixture. According to that, more agitation during and after the mixing step is preferred for the hypoeutectic Al-Si system[13]. Figure 6 (c) shows an optical microstructure image of a specimen taken 
from the sample for the experiment named Ex4 that was carried out by re-melting half the sample of the Ex3 at $700^{\circ} \mathrm{C}$ and hence, the melt was directly poured into a hot empty backed-clay crucible heated at $555^{\circ} \mathrm{C}$. The experiment Ex4 represents the conventional solidification. In Figure 6 (c), the dendritic microstructure forms the entire sample. The microstructure results shown in Fig. 5 and Figure 6 would indicate that the Al-Si hypoeutectic alloys can form a non-dendritic microstructure via the CDS process when carefully choosing the $m r, T_{1}, T_{2}$, and the contents of the two precursor alloys.

Figure 7 (a) and (b) show typical microstructure images of the specimens located in the middle and the edge of the sample for the CDS experiment denoted as Ex5 in Table 1, respectively. In Figure 7 (a) and (b) rosette mixed with equiaxed dendritic morphologies would form the microstructure. The microstructure of the experiment $E x 5$ differs from that forming in $E x 1$ and $E x 3$. The experiment Ex5 was carried out to make the $\mathrm{mr}=3$ by decreasing the mass of Alloy 1 (pure aluminum) and increasing the Alloy2 (eutectic alloy). The nucleation starts from Alloy 1 (pure aluminum with $665^{\circ} \mathrm{C}$ ) that is undercooled during the mixing because the mixing happens into the crucible of $A$ lloy 2 that has a lower temperature $\left(580^{\circ} \mathrm{C}\right)[16,17]$. Additionally, The Alloy 2 was increased resulting in to increase in the dendritic microstructure because the Alloy2 is prone to make the dendritic microstructure [17]. Further, the mixture was poured directly after mixing step into an empty steel crucible heated at $580^{\circ} \mathrm{C}$. This leads to making an agitation to the mixture resulting in re-distributing of the morphologies forming in the entire mixture. Further, the stable solid-liquid interface that exists with the growing nuclei would break to become unstable because of the high cooling rate established between the mixture and the steel crucible that has higher thermal diffusivity compared with that for the backed-clay crucible used for Ex1 to Ex4[12, 15]. Figure 7(c) shows an optical microstructure image taken from the sample for Ex6 that was carried out by re-melting half of the sample for the $E x 5$ at $700^{\circ} \mathrm{C}$ and hence, the melt was directly poured into the steel crucible heated at $580^{\circ} \mathrm{C}$. In Figure 7 (c), the dendritic microstructure forms the entire sample. The columnar dendrites dominate the microstructure of the experiment Ex 6 because of the high cooling rate established between the mixture and the steel crucible.

Figure 8 shows an optical microstructure image of the CDS experiment denoted as Ex 7 in Table 1. In Fig. 8, a non-dendritic microstructure forms the entire sample for $E x 7$. The non- dendritic microstructure forms with lower dendrites compared with that for the CDS experiments $E x 1$ to Ex5, although the mixing takes place at a lower mass ratio $(m r=2.6)$ and lower difference in the initial temperature $\left(665-613=42^{\circ} \mathrm{C}\right)$. This happens because the solidification of the Alloy2 (Al-15wt\%Si- hypereutectic alloy) differs from the solidification of hypoeutectic Al-Si alloys that are prone to form the dendritic microstructure. According to Ex7 results and the results reported by Khalaf [38], a new window can be opened of the CDS process at which the two precursor alloys can be chosen as hypoeutectic alloy mixing with hypereutectic alloy to make the resultant alloy.

The CDS process was presented as a casting process depending on mixing two precursor alloys. Therefore, there are unlimited possibilities to choose the contents of the precursor alloys. The alloy Al$6.45 \mathrm{Si}-4 \mathrm{Cu}-0.5 \mathrm{Mg}-0.66 \mathrm{Fe}-0.66 \mathrm{Zn}$ was made by the CDS process in two different ways by choosing the Alloy1 and Alloy2 as illustrated in Table 2. Fig. 9 (a), (b), and (c) show typical microstructure images of 
the specimens located in the middle and the edge of the sample for the CDS experiment denoted as Ex8 and Ex9 indicated in Table 2, respectively. Fig. 9 (a) shows a typical microstructure image of the specimen located in the middle of the CDS experiment denoted as Ex8. In Fig. 9 (a), the dendritic microstructure forms in the entire sample. Fig. 9 (b) and (c) show typical microstructure images of the specimens located in the middle and the edge of the sample for the CDS experiment denoted as Ex9. In Fig. 9 (b) and (c), the non-dendritic microstructure forms the entire sample, where, globular, rosette, and a few equiaxed dendritic morphologies would coexist in the microstructure. The significant result extracted from Ex9 is that the non- dendritic microstructure forms in the entire sample although the difference between the temperatures of the precursor alloys was $11^{\circ} \mathrm{C}$. The parameters illustrated in Table 2 of the experiment Ex 9 indicate that the Alloy 1 and $A / l o y 2$ have 2 and $3^{\circ} \mathrm{C}$ superheat prior to the mixing step, respectively. Further, Alloy 2 has all the copper content and has the lower crucible temperature. One can suggest that lower superheat of Alloy 1 with less than $5^{\circ} \mathrm{C}$ and improving the spontaneous nucleation that may happen to make copious nucleation in the hypoeutectic Al-Si system [11, 16].

\section{Conclusion}

This study dedicates to changing the microstructure of the hypoeutectic Al-Si alloys from dendritic to non-dendritic microstructure by the controlled diffusion solidification process (CDS). Nine experiments representing the CDS process and conventional casting were carried out in this study. Pure aluminum and hypoeutectic alloys would be employed as the first precursor alloy while eutectic alloy for Al-Si system and Al-Cu system (used for comparison), hypoeutectic Al-Si alloys, and hypereutectic Al-Si alloys would be employed as the second precursor alloy (Alloy2), where Alloy 1 and Alloy 2 would be mixed with a mass ratios of $8.3,6,4.5,3$, and 2.6. The mixing of Alloy 1 into Alloy 2 happens directly and through a $9 \mathrm{~mm}$ diameter funnel. The Al-Si and Al-Cu experiments that were mixed through the funnel were simulated by using Ansys fluent software to present a better understanding of the distribution of Alloy 2 in the mixture. The results of this study are summarized below:

1. The CDS process would change the microstructure of the hypoeutectic Al-Si alloys to a non-dendritic microstructure. The process presents many ways to choose the precursor alloys.

2. The non-dendritic microstructure forms the sample when pure aluminum with around $5^{\circ} \mathrm{C}$ superheat would be used as a first precursor alloy. In this case, increasing the mass ratio by decreasing the mass of Alloy2 represents a solution to form the non-dendritic microstructure with lower dendrites forming in the CDS sample.

3. The simulation results carried out by Ansys software for the CDS process give a better explanation for the Alloy 1 and Alloy2 distribution in the mixture during the mixing step.

4. The simulation results show that the air interrupted during the mixing step form between the Alloy 1 stream and Alloy 2 depending on the density and the viscosity of the mixed alloys. 
5. The hypereutectic Al-Si alloys can be employed as Alloy2 to form a non-dendritic microstructure for hypoeutectic Al-Si alloys. Where using the hypereutectic Al-Si alloys increases the mass ratio and changes the solidification pathway of Alloy2 leading to reduce the dendrites forming during the solidification of the mixture.

6. The superheat of $A$ lloy 1 and $A$ Alloy2 less than $5^{\circ} \mathrm{C}$ is preferred to change the microstructure of hypoeutectic alloys when using alloys as Alloy1. This gives a better solution when the difference in temperature between the two precursor's alloys is less than $20^{\circ} \mathrm{C}$ for the alloys under study.

7. Pure aluminum employed as Alloy 1 needs more undercooling to form the non-dendritic microstructure compared with employing an alloy.

The variation in choosing the precursor alloys in this study explains the parameters preferred to form the non-dendritic microstructure in hypoeutectic Al-Si alloys.

\section{Abbreviations}




\begin{tabular}{|c|c|c|c|}
\hline Alloy1 & First precursor alloy & $T$ & Temperature (K) \\
\hline Alloy2 & Second precursor alloy & $T_{1}$ & Alloy1 Temperature (K) \\
\hline Alloy3 & Resultant alloy. & $T_{2}$ & Alloy2 Temperature (K) \\
\hline$A_{L}$ and $B_{L}$ & Variables of density & $T_{L}$ & Liquidus temperature $(\mathrm{K})$ \\
\hline$C_{1}$ & Composition of Alloy1 (wt \%) & $T_{S}$ & Liquidus temperature $(\mathrm{K})$ \\
\hline$C_{2}$ & Composition of Alloy2 (wt \%) & $T_{L 1}$ & liquidus temperature of Alloy $1(\mathrm{~K})$ \\
\hline$C_{A l}$ & Aluminum concentration (wt\%) & $T_{L 2}$ & liquidus temperature of $A / l o y 2(\mathrm{~K})$ \\
\hline$C_{C u}$ & Copper concentration (wt\%) & $T \infty$ & Bulk temperature $(\mathrm{K})$ \\
\hline$C_{O}$ & Composition of Alloy3 (wt \%) & $U$ & Velocity $\left(\mathrm{ms}^{-1}\right)$ \\
\hline$C_{P}$ & Specific heat $\left(\mathrm{Jkg}^{-1} \mathrm{~K}^{-1}\right)$ & $\beta_{T}$ & temperature dependence Variable \\
\hline$c_{S i}$ & Silicon concentration (wt\%) & $\beta_{C}$ & concentration dependence Variable \\
\hline$C_{\text {Solute }}$ & Solute concentration (wt\%) & $\mu$ & Viscosity (mPa) \\
\hline $\mathrm{H}_{\mathrm{sol}}$ & Heat of solution $(\mathrm{J})$ & $\Omega$ & Regular solution \\
\hline$m 1$ & Mass of Alloy1 (kg) & K & Thermal conductivity $\left(\mathrm{WK}^{-1} \mathrm{~m}^{-2}\right)$ \\
\hline$m 2$ & Mass of Alloy2 (kg) & $\boldsymbol{\sigma}$ & Surface tension $\left(\mathrm{Nm}^{-1}\right)$ \\
\hline$m r$ & Mass ratio $\left(\mathrm{m}_{1} / \mathrm{m}_{2}\right)$ & $\rho$ & Density $\left(\mathrm{kgm}^{-3}\right)$ \\
\hline$N$ & Number of species & $\eta_{\text {Alloy }}$ & Multy component viscosity ( $\mathrm{mPa}$ ) \\
\hline
\end{tabular}

\section{Declarations}

\section{Acknowledgment}

The authors are grateful to Mr. Doug Culley, Mr. Xiaogang Li, and Xiaochun Zheng for assisting in this research project.

\section{Author contribution}

Abbas A. Khalaf designed the study, performed the research, analyzed the data, wrote the paper, conducted experiments and data processing.

\section{Funding}


The authors declare that no funds, grants, or other support were received during the preparation of this manuscript.

\section{Availability of data and materials}

The experimental and simulation data is transparent.

\section{Ethics approval}

This article does not contain any studies with human participants performed by any of the authors.

\section{Consent to participate}

This work was conducted with no human test subjects.

\section{Consent for publication}

This work has consent for publication

\section{Conflict of interest}

The authors declare that they have no conflict of interest.

\section{References}

1. Ye H (2003) An Overview of the Development of Al-Si-Alloy Based Material for Engine Applications. J Mater Eng Perform 12:288-297. https://doi.org/10.1361/105994903770343132

2. Ahn SS, Pathan S, Koo JM et al (2018) Enhancement of the mechanical properties in Al-Si-Cu-Fe-Mg alloys with various processing parameters. Materials (Basel) 11. https://doi.org/10.3390/ma11112150

3. Timpel M, Wanderka N, Schlesiger R et al (2012) The role of strontium in modifying aluminiumsilicon alloys. Acta Mater 60:3920-3928. https://doi.org/10.1016/j.actamat.2012.03.031

4. Mirzadeh H, Niroumand B (2009) Fluidity of Al-Si semisolid slurries during rheocasting by a novel process. J Mater Process Technol 209:4977-4982.

https://doi.org/10.1016/j.jmatprotec.2009.01.020

5. Saha D, Shankar S, Apelian D, Makhlouf MM (2004) Casting of aluminum-based wrought alloys using controlled diffusion solidification. Metall Mater Trans A 35:2174-2180. https://doi.org/10.1007/s11661-004-0167-8

6. Khalaf AA, Ashtari P, Shankar S (2009) Controlled Diffusion Solidification (CDS): Conditions for NonDendritic Primary Aluminum Phase in Al-Cu Hypo-Eutectic Alloys. In: The Third International Symposium, TMS (The Minerals, Metals \& Materials Society). pp 215-222 
7. Saha D, Shankar S, Apelian D, Makhlouf MM (2005) Controlled diffusion solidificationManufacturing net shaped al-based wrought alloy parts. In: Proceedings of the John Campbell Honorary Symposium Edited by P. Crepeau and M. Tiryakioglu TMS (The Minerals, Metals \& Materials Society)

8. Ashtari P, Birsan G, Khalaf A et al (2011) Controlled diffusion solidification of 2024,6082 and $7075 \mathrm{Al}$ alloys via tilt-pour casting process. Int J Met 5:43-63

9. Ghiaasiaan R, Zeng X, Shankar S (2014) Controlled Diffusion Solidification (CDS) of Al-Zn-Mg-Cu (7050): Microstructure, heat treatment and mechanical properties. Mater Sci Eng A 594:260-277

10. Khalaf AA, Shankar S (2011) Favorable environment for a nondendritic morphology in controlled diffusion solidification. Metall Mater Trans A 42:2456-2465

11. Khalaf AA (2010) Controlled diffusion solidification: process mechanism and parameter study. Ph.D Thesis. McMaster University

12. Khalaf AA, Shankar S (2020) Mechanism of Anomalous Grain Formation During Controlled Diffusion Solidification. https://doi.org/10.1007/s11837-020-04198-1. JOM

13. Khalaf AA, Shankar S (2012) Effect of mixing rate on the morphology of primary Al phase in the controlled diffusion solidification (CDS) process. J Mater Sci 47:8153-8166

14. Khalaf AA, Ashtari P, Shankar S (2009) Formation of nondendritic primary aluminum phase in hypoeutectic alloys in controlled diffusion solidification (CDS): A hypothesis. Metall Mater Trans B 40:843-849

15. Khalaf AA (2016) Mechanism of controlled diffusion solidification: Mixing, nucleation and growth. Acta Mater 103:301-310

16. Khalaf AA, Takrouri KJ (2020) Spontaneous nucleation in hypoeutectic Al - Cu system by controlled diffusion solidification process. SN Appl Sci 2:1337

17. Khalaf AA (2021) Studying of Non-Dendritic Microstructure Forming in Controlled Diffusion Solidification. Int J Met. https://doi.org/10.1007/s40962-021-00590-y

18. Ghiaasiaan R, Shankar S (2020) Microstructure, Intermetallic Phases, and Fractography of the Cast Al-5.8Zn-2.2Mg-2.5Cu Alloy by Controlled Diffusion Solidification. Metall Mater Trans A Phys Metall Mater Sci 51:4711-4726. https://doi.org/10.1007/s11661-020-05885-Z

19. Ghiaasiaan SR, Khalaf AA, Zheng X, Shankar S (2012) Near net shaped casting of 7050 Al wrought alloy by CDS process: Microstructure and mechanical properties. In: Light Metals 2012. pp 313-318

20. Ghiaasiaan SR, Shankar S, Apelian D (2014) Control Diffusion Solidification (CDS): An Overview of Mechanism and Application. Shape Cast 5th Int Symp 2014 89-97. https://doi.org/10.1002/9781118888100.ch11

21. Ghiaasiaan SR, Khalaf AA, Zheng X, Shankar S (2012) Near Net Shaped Casting of 7050 Al Wrought Alloy By CDS Process: Microstructure and Mechanical Properties. In: TMS (The Minerals, Metals \& Materials Society). pp 313-318 
22. Ghiaasiaan SR (2015) Controlled diffusion solidification process (CDS) of Al-7XXX wrought alloys: heat treatment, microstructure, and mechanical properties. McMaster University

23. Yang X, Li Y, Luo X, mei et al (2019) Microstructural evaluation and mechanical properties of 7075 aluminum alloy prepared by controlled diffusion solidification. China Foundry 16:238-247. https://doi.org/10.1007/s41230-019-9059-9

24. Pourgharibshahi M, Divandari M, Saghafian Larijani H, Ashtari P (2017) Controlled diffusion solidification processing: A review. J Mater Process Technol 250:203-219. https://doi.org/10.1016/j.jmatprotec.2017.07.018

25. Symeonidis K (2009) The controlled diffusion solidification process: fundamentals and principles.Ph.D Thesis. Worcester Polytechnic Institute (WPI)

26. Apelian D, Makhlouf MM, Saha D (2006) CDS Method for Casting Aluminium-Based Wrought Alloy Compositions: Theoretical Framework. In: Materials Science Forum. pp 1771-1776

27. Ashtari P, Birsan G, Khalaf A, Shankar S (2011) Controlled diffusion solidification of 2024,6082 and $7075 \mathrm{Al}$ alloys via tilt-pour casting process.Int J Met43-63

28. Wu M, Ludwig A (2009) Modeling equiaxed solidification with melt convection and grain sedimentation-II. Model verification. Acta Mater 57:5632-5644. https://doi.org/10.1016/j.actamat.2009.07.067

29. Valencia JJ, Quested PN (2008) ASM Handbook Committee/Thermophysical Properties

30. Kurz W, Fisher DJ (1984) Fundamentals of Solidification, Second Edition. Trans Tech Publications, Aedermannsdorf

31. Dogan A, Arslan H (2018) Thermophysical properties of $\mathrm{Cu}-\mathrm{In}-\mathrm{Sn}$ liquid Pb-free alloys: viscosity and surface tension. Philos Mag 98:37-53. https://doi.org/10.1080/14786435.2017.1392053

32. Zhang F, Du Y, Liu S, Jie W (2015) Modeling of the viscosity in the AL-Cu-Mg-Si system: Database construction. Calphad Comput Coupling Phase Diagrams Thermochem 49:79-86. https://doi.org/10.1016/j.calphad.2015.04.001

33. Yoshikawa T, Morita K (2006) Activity measurements of Al and $\mathrm{Cu}$ in $\mathrm{Si}-\mathrm{Al}$ - Cu melt at 1273 and $1373 \mathrm{~K}$ by the equilibration with molten $\mathrm{Pb}$. J Alloys Compd 420:136-144. https://doi.org/10.1016/j.jallcom.2005.10.071

34. Miettinen J et al (2019) Thermodynamic Description of the Fe-Al-Mn-Si-. C System for Modelling Solidification of Steels

35. Wang F, Liu ZL, Qiu D et al (2015) The Influence of the Effect of Solute on the Thermodynamic Driving Force on Grain Refinement of Al Alloys. Metall Mater Trans A Phys Metall Mater Sci 46:505515. https://doi.org/10.1007/s11661-014-2599-0

36. Schmitz J, Brillo J, Egry I, Schmid-Fetzer R (2009) Surface tension of liquid Al-Cu binary alloys. Int J Mater Res 100:1529-1535. https://doi.org/10.3139/146.110221

37. Kobatake H, Brillo J, Schmitz J, Pichon PY (2015) Surface tension of binary Al-Si liquid alloys. J Mater Sci 50:3351-3360 
38. Khalaf AA (2022) Metastable transition temperature in undercooled hypereutectic Al-Si alloys.Scr Mater210

\section{Figures}

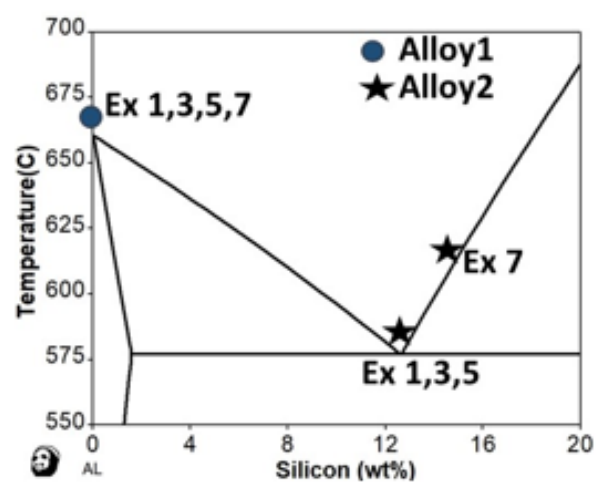

(a)

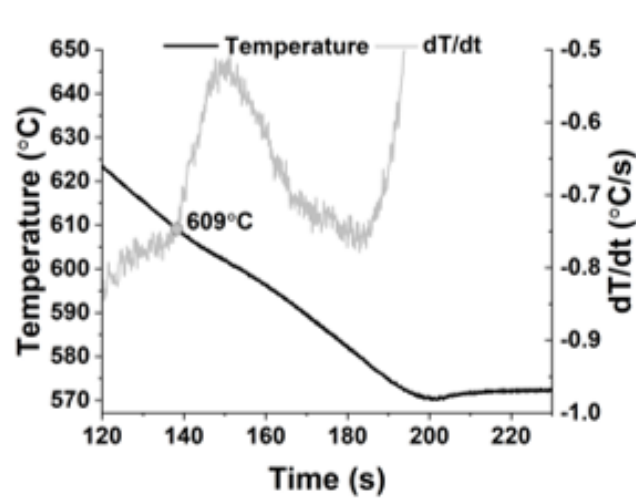

(d)

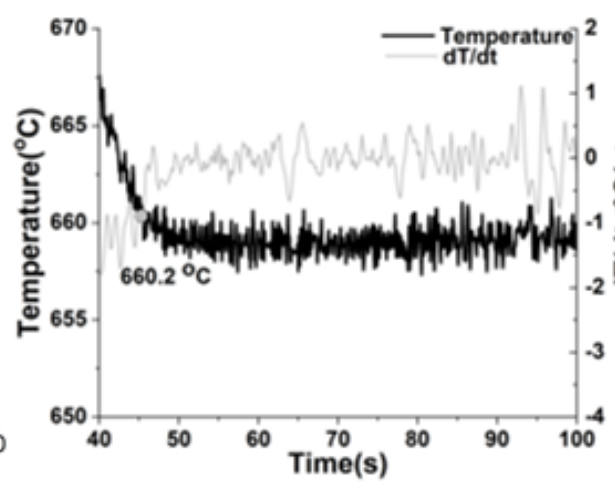

(b)

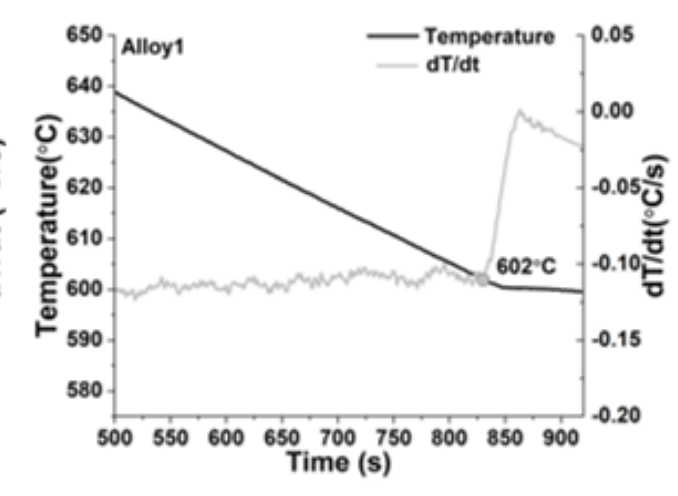

(e)

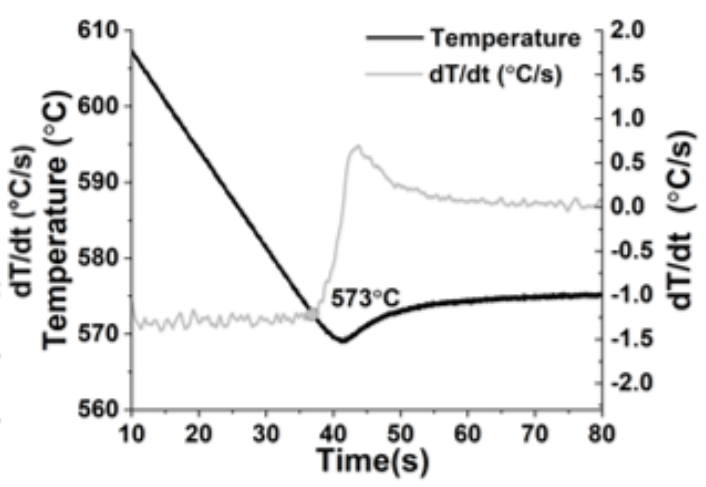

(c)

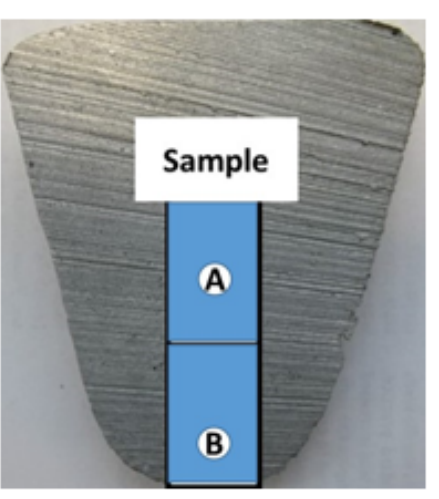

(f)

\section{Figure 1}

(a) Al-Si phase diagram showing the location of Alloy 1 and Alloy2 prior to mixing step, (b), (c), and (d) cooling curve and first derivative curve for pure aluminum, Al-12.6 wt\%Si, and $\mathrm{Al}-15 \mathrm{wt} \% \mathrm{Si}$, respectively, (e) cooling curve and first derivative curve for the Alloy 1 for Ex9 involved in Table 2, and (f) half of solidified sample of the experiments showing the locations of the middle and the edge specimens taken for the microstructure image. 


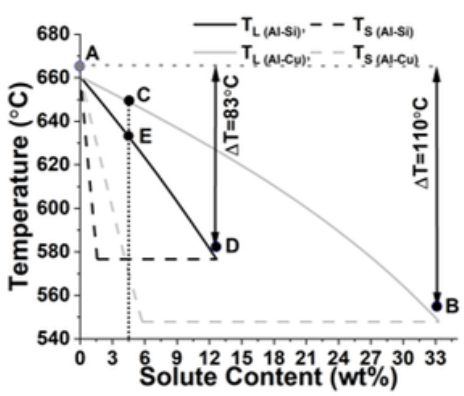

(a)

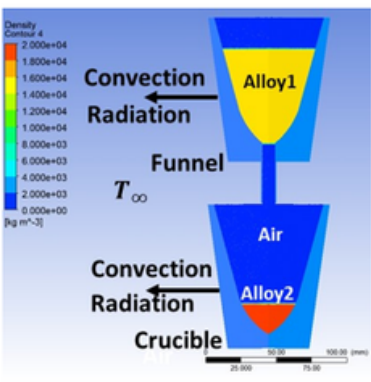

(b)

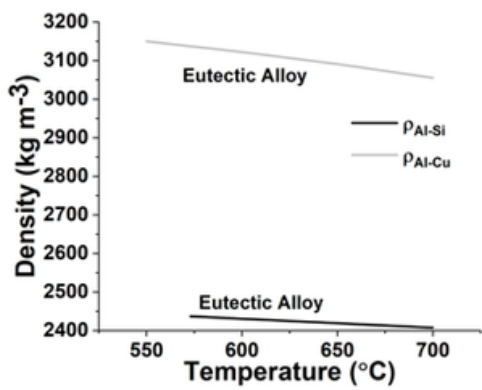

(c)

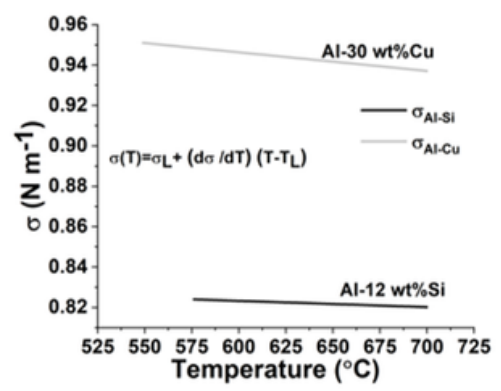

(d)

Figure 2

(a) Al-Si and Al-Cu phase diagram for hypoeutectic area showing the liquidus and solidus lines, (b) initial condition of the density for air, Alloy1 and Alloy2 coexisting in the model solved by ANSYS software (c) comparison between the density of $\mathrm{Al}-12.6 \mathrm{wt} \% \mathrm{Si}$ and $\mathrm{Al}-33 \mathrm{wt} \% \mathrm{Cu}$, and (d) comparison between the surface tension of Al- $12 \mathrm{wt} \% \mathrm{Si}$ and $\mathrm{Al}-30 \mathrm{wt} \% \mathrm{Cu}$.
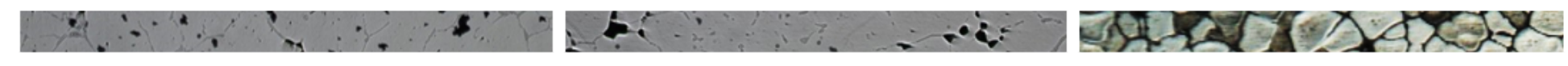

\section{Figure 3}

Typical microstructure images of the sample for the CDS experiments named Ex 1 and $E x 2$ involved in Table 1, (a) middle specimen for Ex1, (b) edge specimen for Ex1, (c) middle specimen for Ex2, (d) edge specimen for Ex2, and (e) (a) thermal curves of the experiment named Ex1 and Ex2 shown in Table 1. 


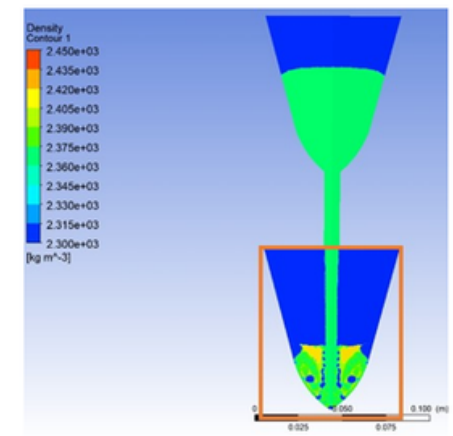

(a)

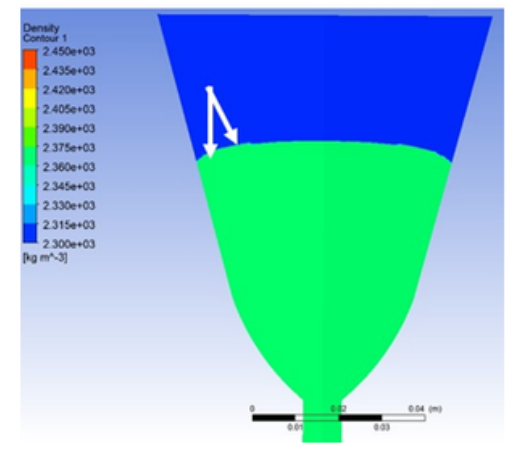

(b)

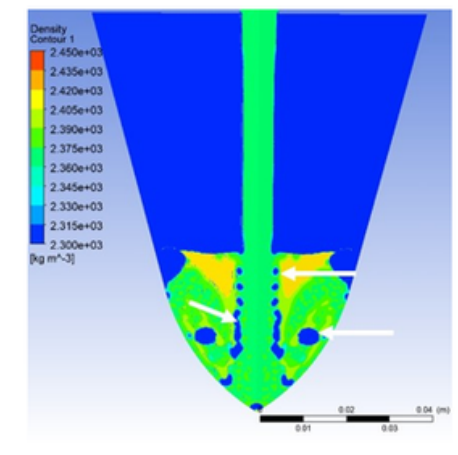

(c)

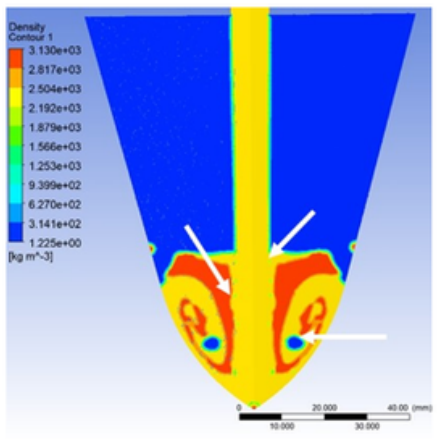

(d)

\section{Figure 4}

(a) density distribution at $0.4 \mathrm{~s}$ of Ex1 experiment for Al-Si system, (b) magnified image at funnel area shown in Fig 4(a), (c) magnified image at the crucible area pointed by a square shown in Fig 4(a) for Ex1, (d) magnified image of density distribution result at $0.4 \mathrm{~s}$ for the crucible area of Ex2 experiment for Al-Cu system. 


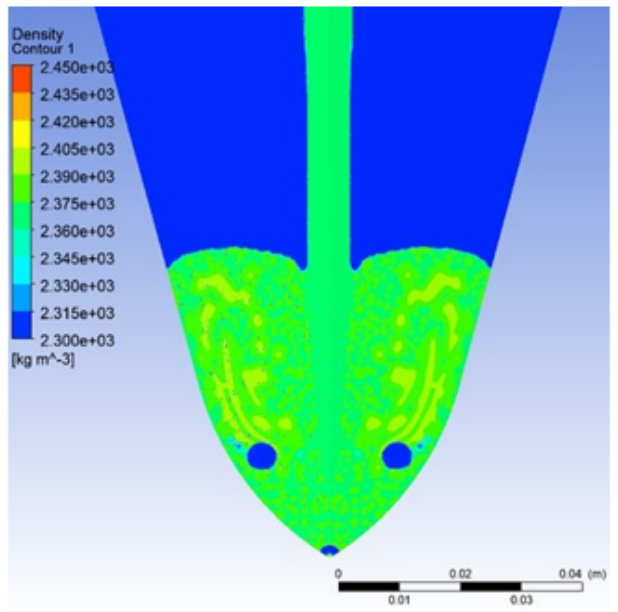

(a)

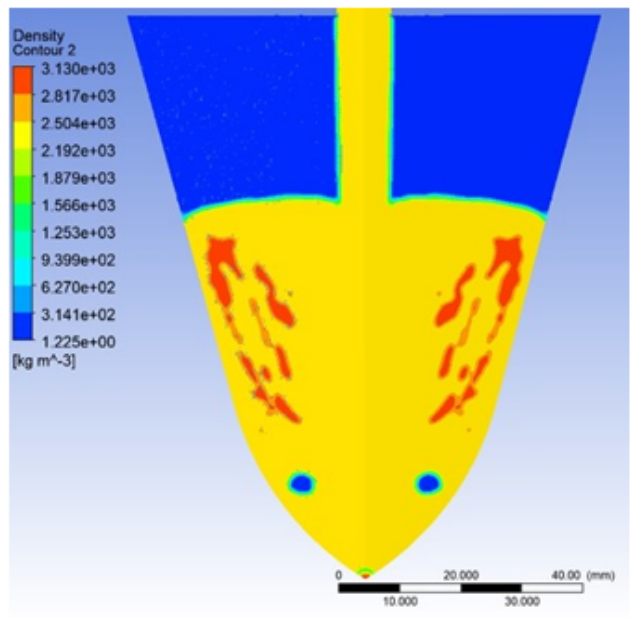

(d)

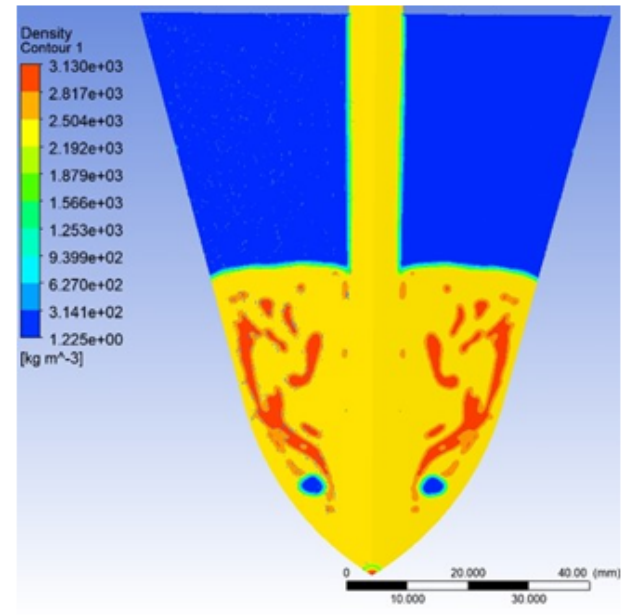

(b)

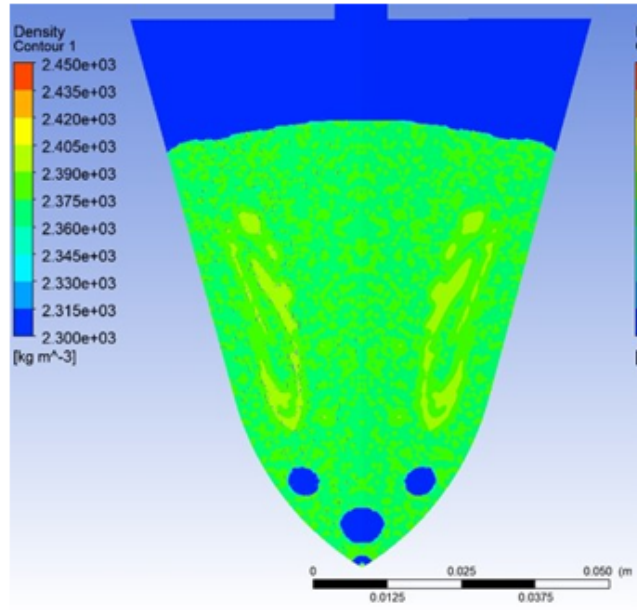

(e)

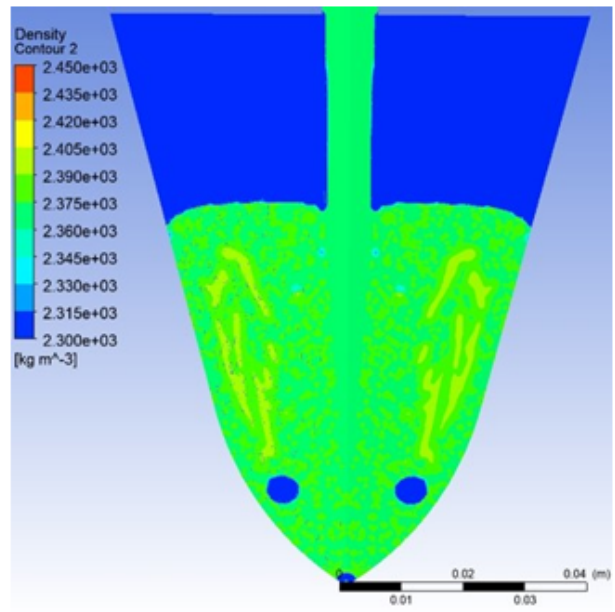

(c)

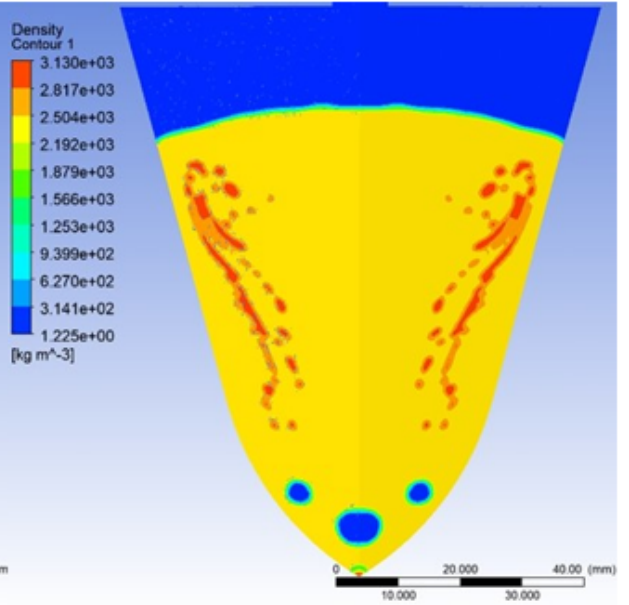

(f)

\section{Figure 5}

Simulation results of density distribution for Ex 1 and Ex2 experiments, (a) and (b) taken at $0.8 \mathrm{~s}$, (c) and (d) taken at $1.2 \mathrm{~s},(\mathrm{e})$ and $(\mathrm{f})$ taken at the end of mixing, respectively.

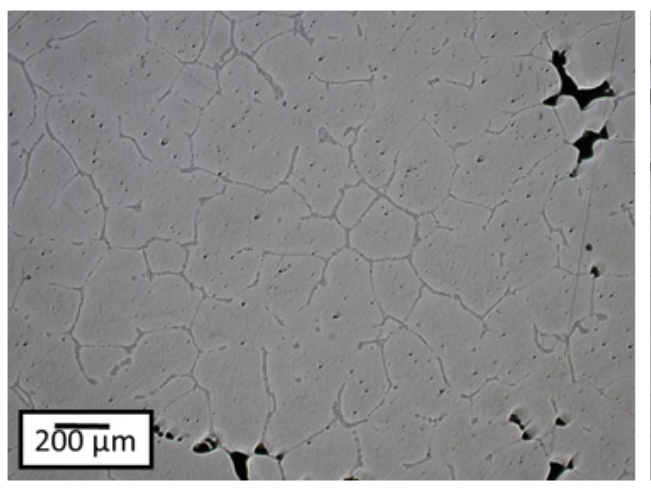

(a)

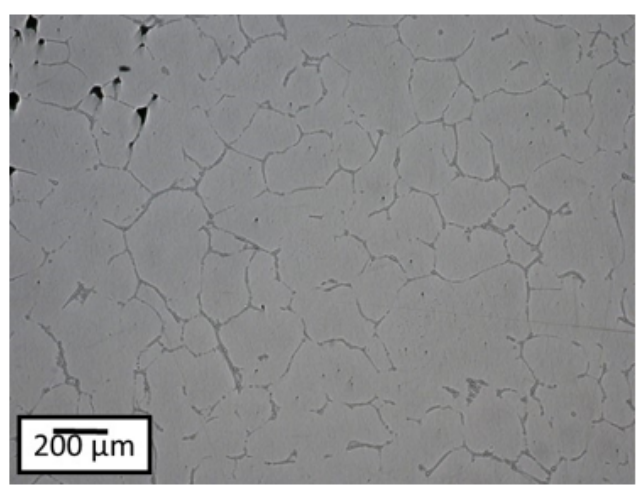

(b)

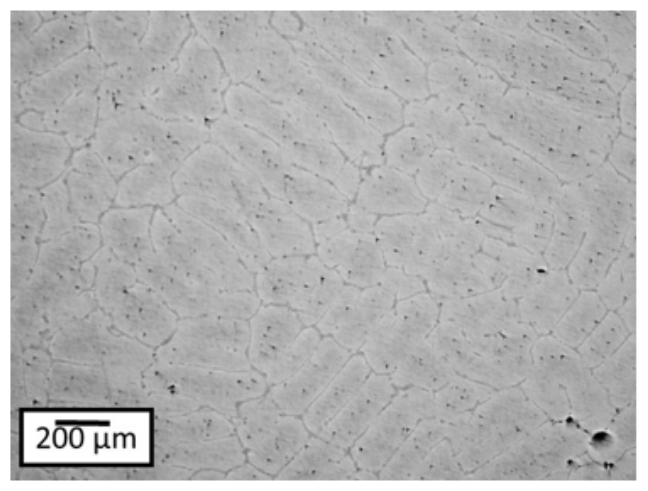

(c) 


\section{Figure 6}

(a) optical microstructure image taking from the middle of the sample for the experiment named Ex3 shown in Table 1, (b) optical microstructure image taking from the edge of the sample for the experiment named Ex3 in Table 1 and (c) optical microstructure image taking from the middle of the sample for the experiment named Ex4 in Table 1.

\section{Figure 7}

(a) optical microstructure image taking from the middle of the sample for the experiment named Ex5 in Table 1, (b) optical microstructure image taking from the edge of the sample for the experiment named Ex5 in Table 1 and (c) typical microstructure image taking from the middle of the sample for the experiment named Ex6 in Table 1.

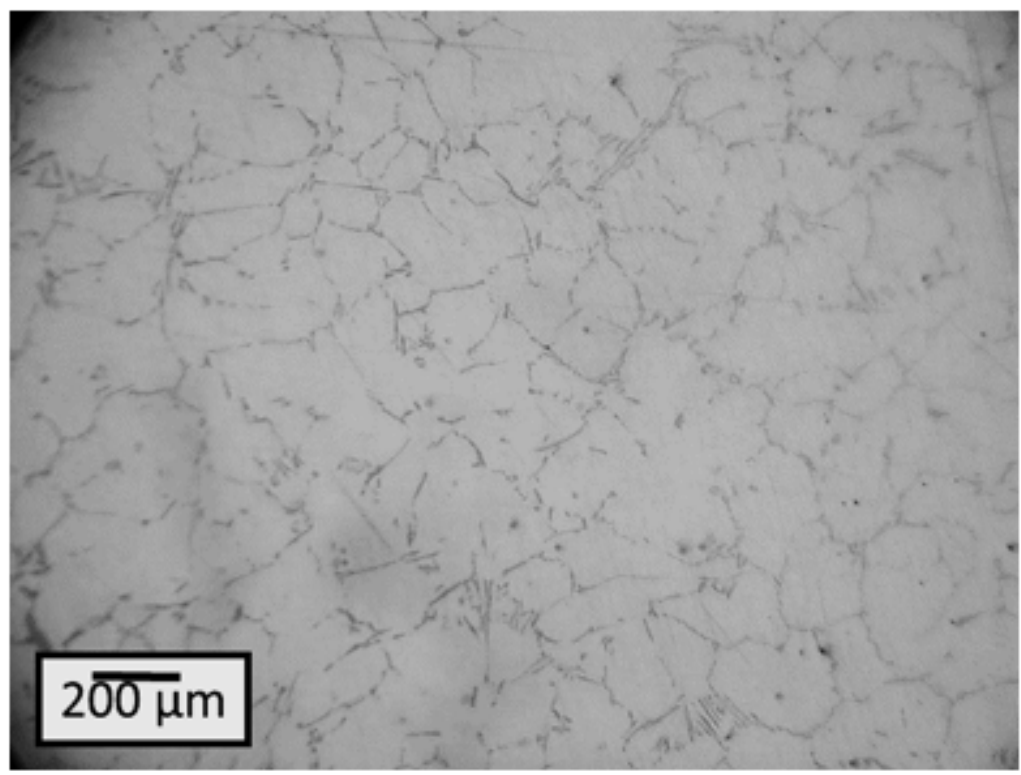

\section{Figure 8}

typical microstructure image of the sample for the experiment named Ex7 involved in Table 1

\section{Figure 9}

(a) optical microstructure image taken from the middle of the sample for the experiment named Ex8 in Table 2, (b) optical microstructure image taken from the middle of the sample for the experiment named Ex9 in Table 2, and (c) optical microstructure image taken from the edge of the sample for the experiment named Ex9. 


\section{Supplementary Files}

This is a list of supplementary files associated with this preprint. Click to download.

- GraphicalAbstract.jpg 